\title{
Aprendizagem Significativa: passível de ser trabalhada no Ensino Fundamental I
}

\author{
Significant Learning: able to be worked in Basic Education I
}

Lucas Oliveira Costa Silva ${ }^{\dagger^{*}}$, Marinéa Figueira Rodrigues

\begin{abstract}
Resumo
Como citar esse artigo. Silva, L.O.C; Rodrigues, M.F. Aprendizagem Significativa: passível de ser trabalhada no Ensino Fundamental I. Revista Mosaico. 2017 Jan./Jun.; 08 (1): 40-42.

Esta pesquisa tem como objetivo investigar a importância da Aprendizagem Significativa no trabalho do professor com alunos do Ensino Fundamental I, uma vez que trata da interação entre o conhecimento novo e o já existente na estrutura cognitiva do aprendiz. Buscou-se, portanto a teoria de Ausubel e Novak que pesquisam como ocorre a aquisição de um novo conhecimento, como ele se transforma e ganha significado.

Palavras-Chave: Aprendizagem significativa. Conhecimentos prévios. Ensino Fundamental I
\end{abstract}

\begin{abstract}
This study investigates the importance of Significant Learning in the teachers' work with elementary students I, since it deals with the interaction between new and existing knowledge in the cognitive structure of the learner. The theory of Ausubel and Novak was applied as it focusses on the acquisition of new knowledge, how this knowledge is transformed, and gains meaning.

Keywords: Meaningful learning. Previous knowledge. Basic Education I.
\end{abstract}

\section{Introdução}

O objetivo deste texto é o de destacar a importância da aprendizagem significativa, em particular no Ensino Fundamental I. Portanto, partiu-se do conceito de aprendizagem significativa segundo Ausubel (1968) e Novak enfocando como ocorre a aprendizagem dos novos conhecimentos na estrutura cognitiva do aprendiz.

Sabemos que um dos fatores fundamentais para o processo da aprendizagem significativa é a compreensão de como ocorre à absorção dos novos conhecimentos, como são compreendidos, organizados e acomodados no cérebro humano, levando os docentes a repensarem a sua forma de ensinar e transmitir conhecimentos para seus alunos.

\section{Aprendizagem Significativa - conceituação}

Segundo Tavares (2004) na década de 60, David Ausubel (1980-2003) sustentou a sua teoria da aprendizagem significativa, na qual preconizava a aprendizagem de significados (conceitos) como aquela fundamental para seres humanos, salientando que grande parte da nossa aprendizagem acontece de forma receptiva e a humanidade tem-se valido para transmitir as informações ao longo das gerações. Uma de suas contribuições é marcar claramente a distinção entre aprendizagem significativa e a aprendizagem mecânica. Já Moreira (1999), afirma que a Aprendizagem Significativa é o conceito central da teoria de Ausubel, na qual o ensino e a aprendizagem eram vistos como estímulo, resposta e reforço e não como significados. Porém Ausubel insistiu em uma "teoria da aprendizagem significativa", pois para ele é no curso dela que a noção lógica do material se transforma em conceito psicológico para o aprendiz.

\section{Condições para a Aprendizagem Significativa}

A aprendizagem significativa ocorre quando o aluno é capaz de receber novas informações e racionalizar, de forma a construir uma interação entre o seu conhecimento prévio e a informação

Afiliação dos autores: † Discente do curso de pedagogia Na Universidade Severino Sombra.

\$ Possui graduação em Pedagogia pela Universidade Santa Úrsula (1981).Pós - Graduada em Problemas do Desempenho Escolar pela Faculdade de Humanidades Pedro II e Mestrado em Ensino de Ciências da Saúde e do Ambiente pelo Centro Universitário Plínio Leite. Atualmente Coordenadora do Curso de Pedagogia,Professora Assistente II da Universidade Severino Sombra -Vassouras/RJ. 
adquirida.

Ausubel chama de conceito subsunçor, o conhecimento que o indivíduo já possui previamente, ou seja, conceitos e proposições estáveis no indivíduo. Essa estabilidade é de suma importância, pois garante ao aprendiz a possibilidade de conhecer ideias novas, agregando em seus conhecimentos prévios às novas informações. (MOREIRA; MASINI, 2001)

Subsunçor é um conjunto de saberes já existente na estrutura cognitiva que serve de ancoradouro a uma nova informação, para que esta tenha significação para o sujeito. É este elemento que vai dar condições para que o novo aprendizado tenha um novo significado para essa informação.

[...] novas ideias, conceitos, proposições podem ser aprendidos significativamente (eretidos) na medida em que outras ideias, conceitos, proposições relevantes e inclusivos estejam adequadamente claros e disponíveis na estrutura cognitiva do indivíduo e funcione desta forma, como ponto de ancoragem para os primeiros. (MOREIRA, 1999, p.11)

Neste sentido a Teoria da Aprendizagem Significativa se contrapõe a "aprendizagem mecânica" ou "aprendizagem automática", já que as novas informações são apreendidas praticamente sem a interação com os conceitos relevantes existentes na estrutura cognitiva do aprendiz, de forma que a nova informação acaba sendo armazenada de maneira arbitrária e não literal.

Exemplos típicos desse tipo de aprendizagem mecânica ocorrem com aqueles alunos que estudam apenas na véspera das provas e logo em seguida não se recordam mais do que estudaram anteriormente ou mesmo quando o aluno afirma ter estudado tudo, mas na hora de realizar um exercício ou até mesmo uma avaliação, não se acha capaz de resolver as questões que implicam no conhecimento que ele afirmou ter.

\section{Aprendizagem Significativa segundo Novak}

Um grande colaborador do trabalho de Ausubel foi Joseph Novak (1977 - 1981) que anos depois, assumiu a tarefa de refinar, testar e divulgar a teoria. Para tal, a técnica dos mapas conceituais, uma estratégia facilitadora no processo da aprendizagem significativa, dando uma conotação humanista na teoria da aprendizagem significativa. Para Moreira et al. (1997) esta teoria deveria chamar-se, hoje, "Teoria de Ausubel e Novak".

Novak contribuiu com sua teoria de educação, que visa considerar que os seres humanos pensam, sentem e agem e ainda deve ajudar a explicar as melhores maneiras para que a aprendizagem ocorra. Segundo ele, qualquer evento educativo é uma ação para trocar significados e sentimentos entre aprendiz e professor. Um evento educativo é também acompanhado de uma experiência afetiva, através da predisposição para aprender. Essa disposição para aprender está intimamente relacionada com a experiência afetiva que o aprendiz tem no evento educativo, podendo acontecer de duas formas: uma experiência afetiva positiva e construtiva quando o aprendiz tem ganhos em compreensão e reciprocidade, caso contrário, se a experiência afetiva fornegativa, pode gerar sentimentos de inadequação ao aprendiz, pois sente que não está adquirindo um novo conhecimento. O processo de aprender e a aprendizagem significativa acabam se tornando uma relação praticamente circular, pois a aprendizagem significativa requer predisposição para aprender e, ao mesmo tempo, gera este tipo de experiência afetiva.

Segundo Moreira (1999), na Teoria de Novak existem cinco elementos básicos de um número infinito de eventos educativos, a saber: aprendiz, professor, conhecimento, contexto e avaliação.

Para o autor nestes eventos educacionais, um ser humano se apropria de um determinado conhecimento num certo contexto, interagindo com o professor ou educador. Quanto ao processo de avaliação, Novak aborda que em algum momento da vida esses conhecimentos serão passíveis de serem avaliados. Para ele esses cinco elementos colocam como fator central de sua teoria a ideia de que qualquer evento educativo implica numa ação para trocar significados e sentimentos entre o aprendiz e o educador e, portanto também vem acompanhada de uma experiência afetiva.

\section{O uso de Mapas Conceituais na Aprendizagem Significativa}

Segundo Almeida e Moreira (2009, p.4403-1), para Novak os mapas conceituais são ferramentas no processo da aprendizagem significativa, pois são diagramas de significados onde se torna possível a visualização da questão e a relação entre os conceitos. Através deles podemos vizualizar a "organização e representação do conhecimento, hierarquizando conceitos, usualmente colocados dentro de círculos, conectados por linhas e palavras (conectores) que representam as relações entre esses conceitos".

\section{Considerações finais}

A Aprendizagem Significativa é um conceito de grande valia na atualidade, contribuindo, enormemente, para os docentes do Ensino 
Fundamental, pois compreender como ocorre o processo da aprendizagem de maneira ampla torna mais fácil compreender como ela ocorre individualmente. A aprendizagem significativa se aplica a toda forma de aprendizagem, visto que ela tem como foco a transformação da aquisição de uma simples informação em um conhecimento significativo fixado com maior complexidade na estrutura cognitiva do ser humano.

\section{Referências}

ALMEIDA, VoltaireO. e MOREIRA, Marco A. Mapas conceituais no auxílio à aprendizagem significativa de conceitos da óptica física. Revista Brasileira de Ensino de Física, v. 30, n. 4, 4403 (2008). Disponível em:http://www. scielo br/pdf/rbef/ v30n4/v30n4a09.Acesso em 10 MAI 2017.

MOREIRA, M. A.; CABAllero, M. C. e RODRIGUEZ, M. L. Aprendizagem significativa: um conceito subjacente In: Actas del Encuentro Internacional sobre el Aprendizaje Significativo; 1997; Burgos, España. Disponível em: http://www.if.ufrgs.br/ moreira/apsigsubport.pdf. Acesso em 10 MAI 2017.

MOREIRA, Marco Antonio. Teorias de Aprendizagem. São Paulo: UnB, 1999.

MOREIRA, Marco Antônio; MASINI, Elcie. Aprendizagem Significativa: a teoria de David Ausubel. 2 ed. São Paulo: Centauro.2001.

TAVARES, Romero. Aprendizagem Significativa. Revista Conceitos, vol. 5 número 10. Paraíba: UFPB, 2004. Disponível em: http://www.fisica.ufpb. br/ romero/pdf/ReuniaoTrabalhosAcademicos.pdf. Acesso em 05 ABR 2017 